\title{
Penerapan Clustering Pada Laju Inflasi Kota Di Indonesia Dengan Algoritma K-Means
}

\author{
Yudi Prayoga ${ }^{1}$, Heru Satria Tambunan ${ }^{2}$, Iin Parlina ${ }^{3}$ \\ ${ }^{1}$ Mahasiswa Program Studi Sistem Informasi STIKOM Tunas Bangsa, Pematangsiantar \\ ${ }^{2}$ STIKOM Tunas Bangsa, Pematangsiantar, Indonesia \\ ${ }^{3}$ AMIK Tunas Bangsa, Pematangsiantar, Indonesia \\ ${ }^{1}$ prayogayudu668@gmail.com
}

\begin{abstract}
Inflation is a process of increasing prices in general and continuously, related to market mechanisms that can be caused by various factors, among others, increased public consumption, excess liquidity in the market which triggers consumption or even speculation, to include the consequences of inability to distribute goods. Inflation is an indicator to see the level of change, and is considered to occur if the process of price increases takes place continuously and influences each other. Inflation stability is a prerequisite for sustainable economic growth which ultimately benefits the improvement of people's welfare. With the large amount of data generated from the inflation rate of cities in Indonesia it is difficult for the government to classify the inflation rate. The author took the initiative to conduct research on classifying the inflation rate of cities in Indonesia by using the K-Means Clustering Data Mining algorithm, with the number of clusters being 3. The high value group is in cluster 1 (above average), the value group is in cluster 2 (around the average based on the distance used from the centroid), and the low value group is in cluster 3 (below average). flat). By grouping the rate of inflation of cities in Indonesia, it will be known which cities in Indonesia have high, medium and low inflation rates.
\end{abstract}

Keywords: Inflation, Data Mining, K-Means

\begin{abstract}
Abstrak
Inflasi adalah suatu proses meningkatnya harga-harga secara umum dan terus-menerus, berkaitan dengan mekanisme pasar yang dapat disebabkan oleh berbagai faktor, antara lain, konsumsi masyarakat yang meningkat, berlebihnya likuiditas di pasar yang memicu konsumsi atau bahkan spekulasi, sampai termasuk juga akibat adanya ketidaklancaran distribusi barang. Inflasi merupakan indikator untuk melihat tingkat perubahan, dan dianggap terjadi jika proses kenaikan harga berlangsung secara terus-menerus dan saling pengaruh-memengaruhi. Kestabilan inflasi merupakan prasyarat bagi pertumbuhan ekonomi yang berkesinambungan yang pada akhirnya memberikan manfaat bagi peningkatan kesejahteraan masyarakat. Dengan banyaknya data yang dihasilkan dari laju inflasi kota-kota di Indonesia menyulitkan pemerintah mengelompokkan laju inflasi tersebut. Penulis berinisiatif untuk melakukan penelitian tentang mengelompokkan laju inflasi kota-kota di Indonesia dengan menggunakan metode Data Mining algoritma $K$ Means Clustering, dengan jumlah cluster adalah 3. Kelompok nilai tinggi berada di cluster 1 (di atas rata-rata), kelompok nilai sedang berada di cluster 2 (sekitar rata-rata berdasarkan jarak yang digunakan dari centroid-nya), dan kelompok nilai rendah berada di cluster 3 (di bawah rata-rata). Dengan mengelompokkan tingkat laju inflasi kota-kota di Indonesia, maka akan di ketahui kota-kota mana saja di Indonesia yang memiliki laju inflasi tinggi, sedang, dan rendah.
\end{abstract}

Kata Kunci : Inflasi, Data Mining, K-Means 


\section{PENDAHULUAN}

Indonesia adalah negara kepulauan terbesar di dunia yang terdiri dari 17.504 pulau. Dengan populasi hampir 270.054.853 juta jiwa pada tahun 2018, dan sebagai negara yang memiliki banyak kota di setiap provinsinya, tentu tiap kota tersebut memiliki laju inflasi yang berbeda dari tahun ke tahun. Inflasi adalah suatu proses meningkatnya harga-harga secara umum dan terus-menerus, berkaitan dengan mekanisme pasar yang dapat disebabkan oleh berbagai faktor, antara lain, konsumsi masyarakat yang meningkat, berlebihnya likuiditas di pasar yang memicu konsumsi atau bahkan spekulasi, sampai termasuk juga akibat adanya ketidaklancaran distribusi barang. Inflasi merupakan indikator untuk melihat tingkat perubahan dan dianggap terjadi jika proses kenaikan harga berlangsung secara terus-menerus dan saling pengaruh-memengaruhi. Kestabilan inflasi merupakan prasyarat bagi pertumbuhan ekonomi yang berkesinambungan yang pada akhirnya memberikan manfaat bagi peningkatan kesejahteraan masyarakat. Pentingnya pengendalian inflasi didasarkan pada pertimbangan bahwa inflasi yang tinggi dan tidak stabil memberikan dampak negatif kepada kondisi sosial ekonomi masyarakat [1].

Dengan banyaknya data yang dihasilkan dari laju inflasi kota-kota di Indonesia menyulitkan pemerintah mengelompokkan laju inflasi tersebut. Penulis berinisiatif untuk melakukan penelitian tentang mengelompokkan laju inflasi kota-kota di Indonesia dengan menggunakan metode data mining algoritma K-Means Clustering, dengan jumlah cluster adalah 3. Kelompok nilai tinggi berada di cluster 1 (di atas rata-rata), kelompok nilai sedang berada di cluster 2 (sekitar rata-rata berdasarkan jarak yang digunakan dari centroid-nya), dan kelompok nilai rendah berada di cluster 3 (di bawah rata-rata). Dengan mengelompokkan tingkat laju inflasi kota-kota di Indoneisa, maka akan di ketahui kotakota mana saja di Indonesia yang memiliki laju inflasi tinggi, sedang, dan rendah.

Algoritma K-Means Clustering penggunaannya sudah diterapkan di berbagai bidang, beberapa penelitian yang sudah dilakukan menggunakan algoritma tersebut adalah penelitian yang dilakukan oleh [1] berjudul "Penerapan Metode K-Means Untuk Clustering Mahasiswa Berdasarkan Nilai Akademik Dengan Weka Interface Studi Kasus Pada Jurusan Teknik Informatika UMM Magelang”. Peneliti lain juga menggunakan metode data mining seperti [2][3]. Berdasarkan penelitian yang dilakukan, dapat disimpulkan bahwa algoritma K-Means bisa digunakan untuk mengelompokkan mahasiswa berdasarkan IPK dan beberapa atribut mata kuliah. Maka dari itu penulis mengangkat sebuah judul penelitian "Penerapan Clustering Pada Laju Inflasi Kota Di Indonesia Dengan Algoritma K-Means". Yang mana nantinya data yang digunakan dalam data mining untuk mengelompokan data-data kedalam variable atau atribut data, dimana dalam hal ini akan dijelaskan langkah-langkah $K$-means secara manual. Dengan pusat cluster tinggi dengan nilai 8,11 kemudian cluster sedang dengan nilai 5,052 dan cluster rendah dengan nilai 3,455. Data yang akan di cluster dalam hal ini adalah data dari tahun $2013-2017$.

\section{METODOLOGI PENELITIAN}

Data mining adalah suatu metode pengolahan data untuk menemukan pola yang tersembunyi dari data tersebut. Hasil dari pengolahan data dengan metode data mining ini dapat digunakan untuk mengambil keputusan di masa depan. Data mining ini juga dikenal dengan istilah pattern recognition [4][5].

Algoritma K-Means merupakan algoritma clusterisasi yang mengelompokkan data berdasarkan titik pusat cluster (centroid) terdekat dengan data. Tujuan dari K-Means adalah pengelompokkan data dengan memaksimalkan kemiripan data dalam satu cluster dan meminimalkan kemiripan data antar cluster[6]. Ukuran kemiripan yang digunakan dalam cluster adalah fungsi jarak. Sehingga pemaksimalan kemiripan data didapatkan berdasarkan jarak terpendek antara data terhadap titik centroid. Berikut adalah kerangka algoritma $k$-means clustering dapat di lihat pada gambar 1. 


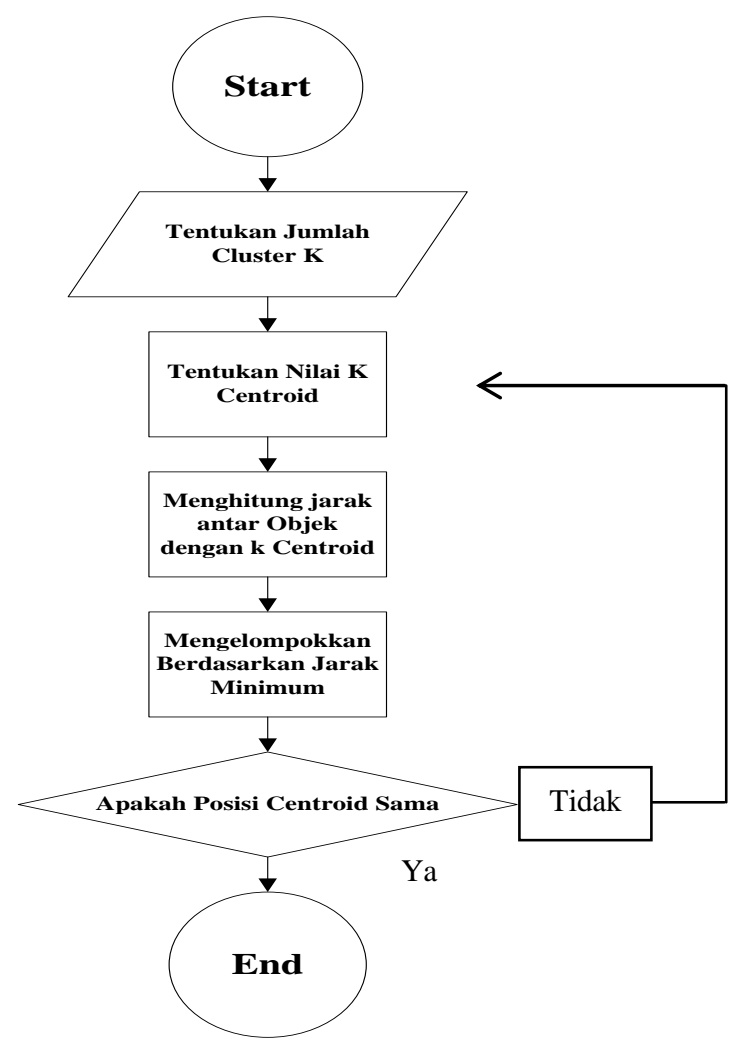

Gambar 1. Flowchart Metode K-Means Clustering

\section{HASIL DAN PEMBAHASAN}

Sumber data penelitian diperoleh dari Badan Pusat Statistik dengan situs https://www.bps.go.id. Data yang digunakan dalam penelitian ini persentase laju inflasi berdasarkan kota dari tahun 2013-2017 yang terdiri dari 83 kota. Data hasil akhir yang nantinya akan diolah melakukan clustering dari berdasarkan provinsi yang dicantumkan dalam 3 cluster yaitu cluster tertinggi, cluster sedang dan cluster terendah.

Dalam melakukan penelitian ini, penulis melakukan analisa data statistik bersifat sekunder yang dimana data diperoleh tidak dari sumbernya langsung, melainkan sudah dikumpulkan dan diolah secara terinci yang dimana data berkaitan dengan permasalahan yang sedang diteliti dapat dilihat pada tabel1.

Tabel 1. Data Inflasi Kota

\begin{tabular}{|c|c|c|c|c|c|c|}
\hline \multirow[t]{2}{*}{ No } & \multirow[t]{2}{*}{ Kota Inflasi } & \multicolumn{5}{|c|}{ Inflasi (Umum) } \\
\hline & & $\begin{array}{c}2013 \\
\text { Tahunan } \\
\end{array}$ & $\begin{array}{c}2014 \\
\text { Tahunan }\end{array}$ & $\begin{array}{c}2015 \\
\text { Tahunan }\end{array}$ & $\begin{array}{c}2016 \\
\text { Tahunan }\end{array}$ & $\begin{array}{c}2017 \\
\text { Tahunan } \\
\end{array}$ \\
\hline 1 & Kota Meulaboh & - & 8,2 & 0,58 & 3,77 & 4,76 \\
\hline 2 & Kota Banda Aceh & 6,39 & 7,83 & 1,27 & 3,13 & 4,86 \\
\hline 3 & Kota Lhokseumawe & 8,27 & 8,53 & 2,44 & 5,6 & 2,87 \\
\hline 4 & Kota Sibolga & 10,08 & 8,36 & 3,34 & 7,39 & 3,08 \\
\hline 5 & Kota Pematang Siantar & 12,02 & 7,94 & 3,36 & 4,76 & 3,1 \\
\hline 6 & Kota Medan & 10,09 & 8,24 & 3,32 & 6,6 & 3,18 \\
\hline 7 & Kota Padangsidimpuan & 7,82 & 7,38 & 1,66 & 4,28 & 3,82 \\
\hline 8 & Kota Padang & 10,87 & 11,9 & 0,85 & 5,02 & 2,11 \\
\hline 9 & Kota Bukittinggi & - & 9,24 & 2,79 & 3,93 & 1,37 \\
\hline 10 & Tembilahan & - & 10,06 & 2,06 & 2,58 & 4,27 \\
\hline 11 & Kota Pekanbaru & 8,83 & 8,53 & 2,71 & 4,19 & 4,07 \\
\hline 12 & Kota Dumai & 8,6 & 8,53 & 2,63 & 3,98 & 4,85 \\
\hline 13 & Bungo & - & 8,99 & 1,29 & 3,11 & 4,25 \\
\hline 14 & Kota Jambi & 8,74 & 8,72 & 1,37 & 4,54 & 2,68 \\
\hline 15 & Kota Palembang & 7,04 & 8,38 & 3,05 & 3,68 & 2,85 \\
\hline
\end{tabular}




\begin{tabular}{|c|c|c|c|c|c|c|}
\hline \multirow[t]{2}{*}{ No } & \multirow[t]{2}{*}{ Kota Inflasi } & \multicolumn{5}{|c|}{ Inflasi (Umum) } \\
\hline & & $\begin{array}{c}2013 \\
\text { Tahunan } \\
\end{array}$ & $\begin{array}{c}2014 \\
\text { Tahunan } \\
\end{array}$ & $\begin{array}{c}2015 \\
\text { Tahunan } \\
\end{array}$ & $\begin{array}{c}2016 \\
\text { Tahunan } \\
\end{array}$ & $\begin{array}{c}2017 \\
\text { Tahunan }\end{array}$ \\
\hline 16 & Kota Lubuklinggau & - & 9,34 & 3,47 & 2,74 & 3,94 \\
\hline 17 & Kota Bengkulu & 9,94 & 10,85 & 3,25 & 5 & 3,56 \\
\hline 18 & Kota Bandar Lampung & 7,56 & 8,36 & 4,65 & 2,75 & 3,14 \\
\hline 19 & Kota Metro & - & 6,5 & 2,67 & 2,92 & 2,32 \\
\hline 20 & Tanjung Pandan & - & 13,14 & 0,88 & 4,92 & 3,97 \\
\hline 21 & Kota Pangkal Pinang & 8,71 & 6,81 & 4,66 & 7,78 & 2,66 \\
\hline 22 & Kota Batam & 7,81 & 7,61 & 4,73 & 3,61 & 4,13 \\
\hline 23 & Kota Tanjung Pinang & 10,09 & 7,49 & 2,46 & 3,06 & 3,37 \\
\hline 24 & Dki Jakarta & 8 & 8,95 & 3,3 & 2,37 & 3,72 \\
\hline 25 & Kota Bogor & 8,55 & 6,83 & 2,7 & 3,6 & 4,59 \\
\hline 26 & Kota Sukabumi & 8,03 & 8,38 & 2,2 & 2,57 & 4,1 \\
\hline 27 & Kota Bandung & 7,97 & 7,76 & 3,93 & 2,93 & 3,46 \\
\hline 28 & Kota Cirebon & 7,86 & 7,08 & 1,56 & 1,87 & 4,36 \\
\hline 29 & Kota Bekasi & 9,46 & 7,68 & 2,22 & 2,47 & 3,01 \\
\hline 30 & Kota Depok & 10,97 & 7,49 & 1,87 & 2,6 & 3,93 \\
\hline 31 & Kota Tasikmalaya & 6,89 & 8,09 & 3,53 & 2,75 & 3,88 \\
\hline 32 & Cilacap & - & 8,19 & 2,63 & 2,77 & 4,41 \\
\hline 33 & Purwokerto & 8,5 & 7,09 & 2,52 & 2,42 & 3,91 \\
\hline 34 & Kudus & - & 8,59 & 3,28 & 2,32 & 4,17 \\
\hline 35 & Kota Surakarta & 8,32 & 8,01 & 2,56 & 2,15 & 3,1 \\
\hline 36 & Kota Semarang & 8,19 & 8,53 & 2,56 & 2,32 & 3,64 \\
\hline 37 & Kota Tegal & 5,8 & 7,4 & 3,95 & 2,71 & 4,03 \\
\hline 38 & Kota Yogyakarta & 7,32 & 6,59 & 3,09 & 2,29 & 4,2 \\
\hline 39 & Jember & 7,21 & 7,52 & 2,31 & 1,93 & 3,52 \\
\hline 40 & Banyuwangi & - & 6,59 & 2,15 & 1,91 & 3,17 \\
\hline 41 & Sumenep & 6,62 & 8,04 & 2,62 & 2,19 & 3,4 \\
\hline 42 & Kota Kediri & 8,05 & 7,49 & 1,71 & 1,3 & 3,44 \\
\hline 43 & Kota Malang & 7,92 & 8,14 & 3,32 & 2,62 & 3,75 \\
\hline 44 & Kota Probolinggo & 7,98 & 6,79 & 2,11 & 1,53 & 3,18 \\
\hline 45 & Kota Madiun & 7,52 & 7,4 & 2,75 & 2,25 & 4,78 \\
\hline 46 & Kota Surabaya & 7,52 & 7,9 & 3,43 & 3,22 & 4,37 \\
\hline 47 & Kota Tangerang & 10,02 & 10,03 & 4,28 & 2,65 & 3,5 \\
\hline 48 & Kota Cilegon & 7,98 & 9,93 & 3,94 & 4,22 & 5,24 \\
\hline 49 & Kota Serang & 9,16 & 11,27 & 4,67 & 3,26 & 5,17 \\
\hline 50 & Singaraja & - & 10,32 & 2,97 & 4,57 & 3,38 \\
\hline 51 & Kota Denpasar & 7,35 & 8,03 & 2,7 & 2,94 & 3,31 \\
\hline 52 & Kota Mataram & 9,27 & 7,18 & 3,25 & 2,47 & 3,59 \\
\hline 53 & Kota Bima & 10,42 & 7,37 & 4,11 & 3,11 & 4,08 \\
\hline 54 & Maumere & 6,24 & 4 & 3,89 & 3,62 & 1,7 \\
\hline 55 & Kota Kupang & 8,84 & 8,32 & 5,07 & 2,31 & 2,05 \\
\hline 56 & Dili & - & - & - & - & - \\
\hline 57 & Kota Pontianak & 9,48 & 9,38 & 6,17 & 3,88 & 3,86 \\
\hline 58 & Kota Singkawang & 6,15 & 9,66 & 4 & 2,58 & 5,23 \\
\hline 59 & Sampit & 7,25 & 7,9 & 5,72 & 2,46 & 3,29 \\
\hline 60 & Kota Palangka Raya & 6,45 & 6,63 & 4,2 & 1,91 & 3,11 \\
\hline 61 & Tanjung & - & 8,8 & 6,69 & 2,18 & 2,4 \\
\hline 62 & Kota Banjarmasin & 6,98 & 7,16 & 5,03 & 3,68 & 3,82 \\
\hline 63 & Kota Balikpapan & 8,56 & 7,43 & 6,26 & 4,13 & 2,45 \\
\hline 64 & Kota Samarinda & 10,37 & 6,74 & 4,24 & 2,83 & 3,69 \\
\hline 65 & Kota Tarakan & 10,35 & 11,91 & 3,42 & 4,31 & 2,77 \\
\hline 66 & Kota Manado & 8,12 & 9,67 & 5,56 & 0,35 & 2,44 \\
\hline 67 & Kota Palu & 7,57 & 8,85 & 4,17 & 1,49 & 4,33 \\
\hline 68 & Bulukumba & - & 9,45 & 2,17 & 1,48 & 4,66 \\
\hline 69 & Watampone & 6,86 & 8,22 & 0,97 & 1,5 & 5,54 \\
\hline 70 & Kota Makassar & 6,24 & 8,51 & 5,18 & 3,18 & 4,48 \\
\hline 71 & Kota Pare-Pare & 6,31 & 9,38 & 1,58 & 2,11 & 3,43 \\
\hline 72 & Kota Palopo & 5,25 & 8,95 & 3,38 & 2,74 & 3,95 \\
\hline 73 & Kota Kendari & 5,92 & 7,4 & 1,64 & 3,07 & 2,96 \\
\hline 74 & Kota Bau-Bau & - & 11,37 & 3,95 & 1,71 & 3 \\
\hline 75 & Kota Gorontalo & 5,84 & 6,14 & 4,3 & 1,3 & 4,34 \\
\hline 76 & Mamuju & 5,91 & 7,88 & 5,07 & 2,23 & 3,79 \\
\hline 77 & Kota Ambon & 8,81 & 6,81 & 5,92 & 3,28 & $-0,05$ \\
\hline 78 & Kota Tual & - & 11,48 & 8,58 & 2,97 & 9,41 \\
\hline 79 & Kota Ternate & 9,78 & 9,34 & 4,52 & 1,91 & 1,97 \\
\hline 80 & Manokwari & 4,63 & 5,7 & 2,77 & 5,75 & 1,78 \\
\hline 81 & Kota Sorong & 7,93 & 6,83 & 6,17 & 2,95 & 1,33 \\
\hline 82 & Merauke & - & 12,31 & 5,76 & 0,82 & 1,25 \\
\hline 83 & Kota Jayapura & 8,27 & 7,98 & 2,79 & 4,13 & 2,41 \\
\hline
\end{tabular}


Untuk mendapatkan hasil dari penelitian yang dilakukan, berikut uraian perhitungan manual proses clustering laju inflasi menggunakan algoritma $K$ Means. Proses clustering dilakukan mulai dari penentuan data yang ingin di cluster. Dalam hal ini variabel data yang ingin di cluster adalah data dari tahun 2013-2017 dan disini peneliti mengambil nilai rata rata dari tahun 2013-2017 sebagai data yang akan di cluster. Berikut adalah cara-cara perhitungan K-Means [7]:

1. Menentukan Data yang Akan Diolah

Data mentah yang digunakan adalah data laju inflasi . Berikut data yang akan digunakan untuk pengolahan metode $K$-Means :

2. Menentukan Jumlah Cluster

Jumlah Cluster yang digunakan pada data laju infansi sebanyak 3 Cluster. Cluster tersebut diantaranya (C1) Tinggi (C2) Sedang dan (C3) Rendah.

3. Menentukan Centroid

Penentuan pusat awal Cluster (Centroid) ditentukan secara manual atau random yang diambil dari data yang ada dalam range. Menentukan Centroid berpengaruh ketika menentukan jumlah Cluster yang digunakan. Nilai Cluster 0 diambil dari data paling rendah, Nilai Cluster 1 diambil dari data rata-rata atau nilai tengah pada data dan Nilai Cluster 2 diambil dari data yang paling tertinggi.

\begin{tabular}{|c|c|}
\hline Cluster & Nilai \\
\hline Centroid 1 & 8,11 \\
\hline Centroid 2 & 5,169512195 \\
\hline Centroid 3 & 3,455 \\
\hline
\end{tabular}

4. Menghitung Jarak dari Centroid

Untuk menghitung jarak antara titik Centroid dengan titik tiap objek menggunakan Euclidian Distance. Rumus untuk menghitung jarak dari Centroid adalah :

$$
D_{(i, f)}=\sqrt{\left(X_{1 i}-X_{1 j}\right)^{2}+\left(X_{2 i}-X_{2 j}\right)^{2}+\cdots+\left(X_{k i}-X_{k j}\right)^{2}}
$$

Maka perhitungan untuk jarak dari Centroid ke-1 adalah sebagai berikut :

$D_{x 1,02}=\sqrt{(4.67-4.67)^{2}+(3.77-3.77)^{2}+(0.58-0.58)^{2}+(8.2-8.2)^{2}}+(0-0)^{2}=0$

$D_{x 2, c 1}=\sqrt{(4.86-4.76)^{2}+(3.13-3.77)^{2}+(1.27-0.58)^{2}+(7.83-8.2)^{2}}+(6.39-0)^{2}=0,473512$

Dan seterusnya sampai dengan $\mathrm{D}_{x 50, c 3}$. Sehingga didapat tabel jarak dari Centroid dan mencari nilai minimal dari ketiga Centroid. Tabel Jarak dari Centroid adalah sebagai berikut :

Tabel 3. Jarak Centroid Iterasi ke-1

\begin{tabular}{llll}
\hline C1 & C2 & C3 & Jarak Terpendek \\
\hline 3,7825 & 0 & 0,8725 & 0 \\
3,414 & 0,473512195 & 1,241 & 0,473512195 \\
2,568 & 0,372487805 & 2,087 & 0,372487805 \\
1,66 & 1,280487805 & 2,995 & 1,280487805 \\
1,874 & 1,066487805 & 2,781 & 1,066487805 \\
1,824 & 1,116487805 & 2,831 & 1,116487805 \\
3,118 & 0,177512195 & 1,537 & 0,177512195 \\
1,96 & 0,980487805 & 2,695 & 0,980487805 \\
3,7775 & 0,837012195 & 0,8775 & 0,837012195 \\
\multicolumn{1}{c}{$\vdots$} & $\vdots$ & $\vdots$ & $\vdots$ \\
\hline
\end{tabular}




\begin{tabular}{llll}
\hline C1 & C2 & C3 & Jarak Terpendek \\
\hline 3,984 & 1,043512195 & 0,671 & 0,671 \\
3,068 & 0,127512195 & 1,587 & 0,127512195 \\
3,075 & 0,134512195 & 1,58 & 0,134512195 \\
2,994 & 0,053512195 & 1,661 & 0,053512195 \\
\hline
\end{tabular}

Selanjutnya dalam metode $K$-Means, perhitungan berhenti apabila Cluster pada iterasi yang dihasilkan sama pada iterasi sebelumnya. Maka selanjutnya mencari Cluster pada iterasi selanjutnya sampai nilai Iterasinya sama. Untuk mencari nilai Centroid selanjutnya dengan menggunakan Centroid baru pada Iterasi ke-1 dengan menjumlahkan nilai sesuai yang tertera pada Cluster di tabel diatas. Adapun Centroid baru untuk mencari Cluster selanjutnya adalah dengan menjumlahkan nilai yang terpilih pada Cluster tersebut kemudian membagikannya sebanyak jumlah nilai sebagai berikut :

$$
\begin{aligned}
C 1= & 0,065142857+0,1 \\
= & (48857143+0,098857143+0.2348571+0+0.260857143+0,288857143+ \\
& 0,122857143+0,321142857+0.5668871+0.167142857+1.725142857) / 11 \\
= & 0.0469722222
\end{aligned}
$$

Maka, data Centroid baru Iterasi ke-5 adalah sebagai berikut :

Tabel 4. Centroid Baru Iterasi Ke-5

\begin{tabular}{cl}
\hline Cluster & \multicolumn{1}{c}{ Nilai } \\
\hline Centorid 1 & 6,384857143 \\
Centroid 2 & 5,066989796 \\
Centroid 3 & 4,311475 \\
\hline
\end{tabular}

Dengan menggunakan langkah - langkah yang sama seperti sebelumnya untuk menentukan Jarak dari Centroid dengan menggunakan Centroid baru Iterasi ke-1.

5. Menentukan Cluster atau Pengelompokan

Dalam menentukan Cluster dengan mencari nilai Cluster berdasarkan nilai minimal dari nilai Cluster dan diletakkan pada Cluster yang sesuai dengan nilai minimal pada Iterasi 1.

Perhitungan manual pada data laju inflasi diatas didapatkan hasil akhir yang dimana pada iterasi 3 pengelompokan data yang dilakukan terhadap 5 cluster dengan iterasi 4 didapatkan hasil yang sama. Hasil dari kedua iterasi tersebut bernilai $\mathrm{C} 1=12, \mathrm{C} 2=46$, dan $\mathrm{C} 3=24$ pada posisi data tiap cluster $\mathrm{x}$. Sehingga posisi cluster pada data tersebut tidak mengalami perubahan lagi maka proses iterasi berhenti. Berdasarkan posisi cluster masing-masing data laju inflasi dan nilai cluster hasil iterasi ke empat maka dapat disimpulkan bahwa:

a) Cluster Tertinggi dengan jumlah data laju inflasi sebanyak 12 kota yaitu, Meulaoh, Banda Aceh, Sibolga, Pematangsiantar, Medan, Bengkulu, Panggkal Pinang, Tanggerang, Cilegeon, Serang, Pontianak, Palangka Raya, Tarakan, Tual.

b) Cluster Sedang dengan jumlah data laju inflasi sebanyak 46 kota yaitu, Lhokseumawe, Padang Sidempuan, Padang, Pekanbaru, Duma, Jambi, Palembang, Lubu Llinggau, Bandar Lampung, Metro, Batam, Tanjung Pinang, Dki Jakarta, Bogor, Sukabumi, Bandung, Bekasi, Depok, 
Tasikmalaya, Puwerkerto, Surakarta, Semarang, Tegal, Malang, Maidun, Surabaya, Singanja, Denpasar, Mataram, Bima, Mumere, Singkawan, Tanjung, Banjirmasir, Balipapan, Samarinda, Manando, Palu, Manando, Balukumba, Watampone, Makasar, Palopo, Bau-Bau, Mamuju, Mabon, Ternate, Sorong, Merauke, Jayapura.

c) Cluster Terendah dengan jumlah sebanyak 24 Kota yaitu, Bukit Tinggi, Tembillahan, Tanjung Padang, Cirebon, Cilacap, Kudus, Probolinggo, Yogyakarta, Jember, Banyuwangi, Sumenep, Kediri, Kupang, Sangkit, Pare -Pare, Kedari Gorontalo, Manokwari.

\section{Kesimpulan}

Berdasarkan pembahasan sebelumnya dapat disimpulkan bahwa:

a) Hasil penelitian yang diperoleh dapat disimpulkan bahwa perhitungan manual excel yang di kombinasikan dengan rapidminer, bahwa metode tersebut mampu untuk menyelesaikan sebuah pengelompokan berdasarkan kota di Indonesia.

b) Hasil yang diperoleh dari metode k-means clustering yang di implementasikan ke dalam rapidminer memiliki nilai validasi yang sama menghasil beberapa cluster yaitu cluster tinggi 12 , cluster rendah 46 , dan sedang 24 yang masing-masing cluster memiliki hasil yang berbeda.

\section{Daftar Pustaka}

[1] R. Adrian, "Penerapan Metode K-Means Untuk Clustering Mahasiswa Berdasarkan Nilai Akademik Dengan Weka Interface Studi Kasus Pada Jurusan Teknik Informatika UMM Magelang," J. Ilm. Semesta Tek., vol. 18, no. 1, hal. 7682, 2015.

[2] S. Sundari, I. S. Damanik, A. P. Windarto, dan H. S. Tambunan, "Analisis KMedoids Clustering Dalam Pengelompokkan Data Imunisasi Campak Balita di Indonesia," Pros. Semin. Nas. Ris. Inf. Sci., no. September, hal. 687-696, 2019.

[3] S. R. Ningsih, I. S. Damanik, A. P. Windarto, dan H. Satria, "Analisis K-Medoids Dalam Pengelompokkan Penduduk Buta Huruf Menurut Provinsi," Pros. Semin. Nas. Ris. Inf. Sci., no. September, hal. 721-730, 2019.

[4] H. Sulastri dan A. I. Gufroni, "Penerapan Data Mining Dalam Pengelompokan Penderita Thalassaemia," vol. 02, hal. 299-305, 2017.

[5] T. Imandasari, E. Irawan, A. P. Windarto, dan A. Wanto, "Algoritma Naive Bayes Dalam Klasifikasi Lokasi Pembangunan Sumber Air," Pros. Semin. Nas. Ris. Inf. Sci., no. November, 2019.

[6] M. G. Sadewo et al., "Penerapan Algoritma Clustering Dalam Mengelompokkan Banyaknya Desa / Kelurahan Menurut Upaya Antisipasi / Mitigasi Bencana Alam Menurut Provinsi Dengan K-Means," vol. 2, hal. 311-319, 2018.

[7] A. P. Windarto, "Implementation of Data Mining on Rice Imports by Major Country of Origin Using Algorithm Using K-Means Clustering Method," Int. J. Artif. Intell. Res., vol. 1, no. 2, hal. 26-33, 2017. 